\title{
ETHICAL COMPETENCE AND POSSIBILITIES OF DIALOGIC EDUCATION
}

\author{
Vladimirs Kincāns \\ Latvijas Universitāte
}

\begin{abstract}
This article is dedicated to the possibilities of shaping ethical competence through dialogic education. The problem of shaping a future specialist's ethical competence in many respects depends on the quality of teaching ethics as a training discipline as well as on the teaching methods. Dialogic education is the most promising form of moral values introduction and ethical competence development.
\end{abstract}

Keywords: Dialogue, communication, morals, ethics, competence, education, pedagogical activities.

\section{Introduction}

A contemporary educational process strives not only for the professional development of a future specialist, but also for the shaping of a future specialist's personal qualities - educating a person with a high level of integrity and ethical culture. That is why, in addition to a high level of professional competence, the model of a trained specialist must also contain the ethical component.

Is the intellectual potential of moral values sufficiently represented in the educational process, in the content of educational programmes and curricular today? It may be said with confidence that the ethical side of development of a future professional is inexcusably neglected and disregarded.

The majority of academic and professional programmes existing in Latvia do not provide for the teaching of ethics letting alone implementing a policy focused on cultivation of moral values. For instance, in the Professional Bachelor's Degree Programme TEACHER of the University of Latvia among 11 qualifications only 2 have in their plans a course of study in Ethics. Many programmes consciously discard humanitarian subjects in favour of strengthening professionally oriented disciplines. The tendency of education towards larger practicalness and pragmaticality is caused by today's realia. Education is concentrated on the solution of immediate questions. The effectiveness of education is basically evaluated in the predicates of efficiency, usefulness and utility. But while solving the pragmatic, immediate problems, education should not lose sight of the semantic basis of European education comprehensive spiritual education of a person and belonging to the Absolute. Education should be perceived as a solution not only to procedural and technological, pragmatic tasks, but also as a motion towards overcoming the finiteness of human existence through the assertion of the ideals of Truth, the 
Good and Beauty. Nothing but pragmatism and the lack of consideration for the spiritual and moral side of training of future specialists in our country predetermined the author's reference to the problem of ethical competence.

The goal of this article: is to describe the possibilities of shaping ethical competence through dialogic education. Dialogue is viewed as a methodological principle for ethical competence development. The author believes the dialoguebased ethical education may be examined as a strategic direction in the development of ethical education. The essence of dialogue consists of the skill to accept the values of another person, to develop own moral values, to formulate one's point of view, to resolve contradictions, and to develop a system of values. Dialogue supports education aimed at the cultivation of ethical competence. Dialogue becomes a procedure leading to the development of future specialist's ethical competence.

Materials and Methods: Author's his research was based on general philosophical positions, thus demonstrating the methodological opportunities of ethical competency building through dialogical education.

\section{Ethical Education}

The basic problem of education today consists in the absence of ideas and purposes. Such ideas are absent, first of all, because in society no one poses any philosophical questions which can do nothing but provide education with a durable basis for its prosperity. The purposes of education must be formulated by society and the state rather than by teachers, theorists of education or institutes and universities. Unfortunately, our state policy in the field of education has neither long-term nor short-term plans to say nothing of strategic purposes. For this very reason, educational establishments, on the basis of their own resources and ideas about the needs of the society, develop programmes, pass expensive accreditation and prepare diverse specialists not thinking about the prosperity of Latvia and morals of future specialists.

Absence of the demand for ethics and moral philosophy in the process of training of future specialists results from the loss by education of its age-old mission - all-round education of a person, and from transforming educational services into the sales market. Describing the state of science and education, Lyotard established that contemporary education is not focused on 'the retention of a human face', but is built on the idea of competence. The competency building approach was maturing and comprehended not inside education; it was rather a reply to the specific request from a professional field. It is focused on the system of education that would answer the needs of the fast-changing world and contemporary labour market. In the new economy, society needs new people who have competences needed by a specific customer. In terms of education it means concentrating on the solution of immediate tasks. Fundamental and humanitarian (ethical) knowledge is subject to radical 
reduction in favour of technological knowledge. Education has been allotted the role of a factory where workers needed by social and economic institutes are being stamped (Lyotard, 1998). Education ceases being an end in itself and is evaluated quite materialistically, i.e. by its efficiency at the labour market. Interest in education is determined not by the tendency towards creative development and moral improvement of a person, but in the possibility of acquiring a prestigious and well paid office. Education has started to adjust to the market and propose itself as the goods. The humanistic mission of education has reduced to the level of training of specialists needed by society and production.

Commercialization of knowledge and utilitarian interest in education is the process that cannot be ignored. At the same time, it is difficult to agree with the fact that orientation to the labour market expels from education the tendency of a person towards moral improvement and development of own creative potentials. The world in which knowledge is merchandise, education - a service, and a student - a client, forces to think about the search for the ways of constructing such educational system in which moral and professional competences mutually supplement each other. This task is not simple since the essence of education and the essence of professional activity principally differ. Personality, its improvement and moral development have always been and remain the purpose of education, whereas the purpose of professional activity is success. The purpose of education and production coincide neither in terms of the form nor in terms of the content, which means that as a minimum it is necessary to reduce the oppositely directed vectors to a common denominator. While solving competence-based tasks, education should not leave out the central idea of education - the spiritual and moral development of a person which requires a fundamental change in the attitude towards ethical aspects of the educational process. According to Hans-Georg Gadamer, education is not just 'the cultivation' of the natural advances of a person, not just 'the perfection' of mental abilities to a certain model significant for one or another historical stage. The essence of education lies in the fact that a person makes him/herself a spiritual being in every respect. The one who gives oneself to details cannot be considered an educated person (Gadamer, 1975).

The isolation of moral and ethical component as the substantiating element in the professional training of a specialist is caused by the marked world tendency towards the humanization of education (Aronowitz, Giroux, 1991). The need for ethical education is obvious, since a person's ethical orientation contributes to the retention of society assigning to its development a proper direction, i.e., drive to the realisation of the good.

Education deprived of the ethical component prepares certified workers but not professionals capable of assuming responsibility for the results of their activity. For knowledge to become a person's authentic obtainment, it should not only be reflected in the consciousness by virtue of its objective value but 
should also be meaningful for a person. Knowledge passed through the needs, interests, feelings and values is opened not only to the mind but also to the heart, which makes it possible for a person to differently see the world, differently feel, wish and act (Зинченко, 1996).

And vice versa, knowledge without morals generates very energetic but dangerous people, well functioning executors, obedient 'screws', but at the same time indifferent, incurious and following 'their' selfish interests. Unfortunately, modern education is oriented to exactly this approach. Today, concentration of knowledge around the axis of moral values is not yet observed, even though humanisation of education, according to the etymology of the word, means focusing on a moral component of cognitive and practical activity. The task of the humanistically oriented education consists in the awakening of the essential forces of a human. Strange as it may seem, a higher school pays no attention to the mind, memory, conscience, will, concern, feeling of responsibility, adherence to principles, civic consciousness and many other moral qualities and professional competences showing spiritual aspects of the student's essential forces. Even if contemporary education focuses its attention on the ethical upbringing, it sooner does it spontaneously rather than purposefully and methodologically apprehended. A change in this state of affairs would be possible if the pedagogical association's efforts, among other things, were focused also on the development in students of understanding of what is going on. It is impossible to teach integrity to students; it is necessary to form readiness for the understanding, ability to reflect and think independently. Together with knowledge translation, education actualises even more vital questions ignoring which would impose a threat to the very bases of human existence. Age-old Kant's questions 'What am I?' and 'What should I do?' have not only preserved their urgency, but are of key importance.

It is important not only to be professionally prepared; a degree to which a person is socially and psychologically adapted to the problems of dynamically developing society is not less important. The ethical qualities of graduates, their skill to associate, and their moral positions appear as the first-rate criteria in the course of their screening and employment. Moral qualities and the civic stance make it possible to reduce the risks of economic instability and consequences of political situation. It is important that after having acquired good education in one or the other field a specialist would work for the good of community rather than to its disadvantage. When choosing a profession, as Benjamin Franklin insisted in his 'moral code', it is necessary, first of all, to consider its ethical side, then - public significance of the profession and only finally - its profitableness. Pursuit of profits is disastrous for the soul of a person and for society (Ayzekson, 2013). In other words, it is important that a graduate of the faculty of law knows the laws well; but his/her having the sense of right and wrong is no less important. A future economist would not only know how to count financial benefit, but also would think about the social responsibility of 
business. For a teacher, moral qualities are not less important than pedagogical knowledge. The moral qualities of a teacher are also the essential aspect of his/her professionalism. The moral and professional qualities of a teacher are indissoluble. Such professional qualities as accuracy, concentration, and benevolence have moral value just like moral qualities are necessary in the performance of a professional duty. The moral qualities of a teacher, such as honesty, good faith, responsiveness, kindness, sympathy, make it possible not just to fulfil professional responsibilities, but also to ensure a positive moral and emotional background, which is so important for a successful pedagogical process. Thus, improvement in the quality of ethical education becomes the vital need of contemporary education.

\section{Ethical Competence}

Ethical competence implies a specialist's ability to recognise ethical problems in life and professional activity, to possess ethical categories, the skill to solve ethical conflicts, the skill to make a moral choice on reasonable grounds.

Ethical competence determines a person's moral choice and moral responsibility for his/her behaviour in any situation. Ethical competence is expressed in a person's skill to achieve self-control, to independently formulate a person's moral responsibilities and to require their fulfilment from him/herself, and to self-evaluate what has been done. In this case it is necessary to note that self-appraisal is accomplished not from the absolutely subjective perspective, but from the perspective of social good.

Ethical competence of a specialist is the skill to follow ethical standards recognised in society and professional environment. It is an ability to use ethical and legal rules regulating the attitude of a person toward a person, to society, to environment. It is a demonstration of respect for people and tolerance to the representatives of another culture. Ethical competence provides readiness for the maintenance of partner relationships, the skill to critically evaluate one's merits and deficiencies, helps to select ways and means for the development of merits and minimisation of actions which are conditioned by the negative traits of nature.

Formation of ethical competence as readiness to use the knowledge, practical skills and abilities acquired in ethics as well as adequate methods of activity in solving practical and theoretical problems associated with moral choice situations is a rather complicated pedagogical task.

First of all, there is sense in talking about a person's ethical competence only if notable attention is paid to ethical education. Knowledge of the basic principles of ethics, the skill to apply ethical doctrines and categories to analyse specific situations provides the necessary theoretical component of ethical education. Therefore, it is difficult to overestimate the role of ethics as a central 
element in training of a professional possessing ethical competence. It is important that curricula included subjects saturated with the ethical content. The point at issue is not only the classical courses in ethics, moral philosophy, history of manners and cultural behaviour. It is important that every discipline, every subject contained an ethical component, and discussion of moral issues would be subjected to practical tasks. Ethical competence is formed from the body of social and humanitarian knowledge in philosophy, history, history of culture, ethics, psychology, sociology, and jurisprudence. Knowledge of communication psychology and business etiquette is also an important source of moral improvement. And it is also important that these events are not one of a kind. Teaching of ethics and moral culture formation must become systemic and continue throughout all the years of instruction.

Secondly, formation of ethical competence is conditioned by the specific character of morals as a form of public consciousness. For this very reason the study of ethics is associated with a number of difficulties. First of all, the danger consists in sliding to moralising, which is most frequently expressed either in the form of dogmatism or in the form of relativism.

At the same time, theorisation should be avoided when teaching ethics. The advantage of the theoretical approach consists in the ability to mobilise philosophical, general sociological knowledge for the understanding of morals. Scholasticism and absolute dissociation with the content of life become a disadvantage. Abstract and theoretical, and speculative reasoning on the theme of morals that is not related to the specific life situations, loses significance and ability to influence the students' values. Not the definitions of the good and evil, conscience, duty, honesty and rightfulness but the understanding of how to retain dignity and human face in the contradictory world of economic competition and political instability are important for a contemporary student and a future specialist. And such formulation of the question is not new. Aristotle said that the task of ethical education is not to know what virtue is, but to be virtuous. Therefore, the problem is in the selection of adequate techniques for presenting ethical materials. Education needs a technique for the development of a person's system of values which would stimulate the genuine interest of students in the basics of integrity and morals, which would actualize their respective needs, feelings, emotions, and thoughts.

Under such conditions, a need arises for a new type of teacher who adheres by a motivational value system and is capable of subject-subject interaction on the basis of equal ethical principles. The idea of actualisation of moral values not through learning, i.e. the transfer of truth, but by means of cooperative pedagogy oriented toward dialogue and giving a possibility to search for its sense is rather promising. The interrelation of dialogue, education and morals is multifaceted and not yet articulated to the end. However, there is no doubt that the dialogic model of education implicitly contains the approaches quite significant for the contemporary ethical education. Their thematisation and 
reflection opens a way for the harmonic integration of dialogic problems into pedagogical practice and revealing their heuristic possibilities for the acquisition of moral values. Moral values can be learned and acquired only by means of finding contradictions in one's behaviour, thoughts, concepts, and nothing but the dialogic structure of communication contributes to this. Joint activity and communication of the teacher and students, their dialogic interrelations are a guarantee of successful acquisition of moral culture and ethical competence development.

\section{Dialogic Approach}

Dialogic communication in the process of forming of future specialists' moral values is one of the key problems of contemporary education. The place of dialogue in education was known already at the dawn of pedagogical studios. However, dialogue in many pedagogical systems fulfilled a rather applied function and was used as a rhetorical figure instead of acting in the form of the so-called 'Socratic dialogue'. Today, it is hardly possible to revive Socratic dialogue the way Socrates did that.

For Socrates, the basic means of the search for the truth were maieutics and irony. When literary translated from the Greek language, maieutics means 'the art of midwifery', i.e., the skill to render aid at birth. By maieutics, Socrates implied the skill of extracting knowledge concealed in a person with the help of questions. As to the method of irony used by Socrates, he pretended to be ignorant or told something opposite to what he was actuality thinking. These methods, isolated from the unique personality of Socrates, cannot create the pedagogical effect characteristic of the Socratic dialogues.

However, if we look at dialogue as the essential form of comprehension of human existence, turning to the idea of Socratic dialogue makes sense due to the fact that exposure to moral values is facilitated by dialogic communication. Dialogue in this case is not understood only as a form of speech act, but as a form of a person's existence in the world, as a means of joint existence of the parties involved in the educational process. One of the most important characteristic features of dialogue is the mutual focus of the communicating parties. Parties participating in a dialogue must face each other, must be interested in and open to each other (Buber, 1995). 'Only participation in the existence of other living beings reveals the sense and basis for our own existence' (Buber, 1995). According to M.M. Bakhtin, the truth is not born and is not located in the head of a person; it is born among people who discover the truth together in the process of their dialogic communication (Бахтин, 1986). Dialogue is an original method of human interrelations. Dialogue and communication is not something secondary happening with the already readymade individuals who previously existed in isolation. On the contrary, dialogue constitutes their existence. In fact, human essence is realised only by means of 
dialogic communication. Dialogue is a process in which 'I' can discover itself and thereby achieves true self-realisation.

Organising dialogic communication is one of the most complicated tasks faced by education. Its purpose is to disclose in a dialogue every person's potential which is possible if a teacher sees in each individual a specific personality, considers his/her moral experience and ethical principles. Dialogic education proclaims the idea that a student is not an object and the end product of social influences, but rather a subject of free, responsible and moral improvement. Dialogic education is not interested in a simple transfer of ethical data and information to students. In contrast to the traditional course of ethics aimed, in the first place, at the transfer of information, dialogue does not imply moralising and precepts. Dialogue rests on the formulation of questions which change the moral horizon and make it possible for a student to strengthen his/her beliefs and/or carry out the overestimation of values. Platonic 'Paideia', which has not lost its urgency today, emphasises the importance of the way which every student must take independently changing him/herself in the tendency toward the ideal of spiritual and moral perfection. Socrates communicated to his students something more than only knowledge. The very death of Socrates attested to the fact that there are things which are impossible to express unambiguously with the help of concepts and definitions. Any person can recall his/her teachers and educators who have played the decisive role in his/her professional and moral formation. Most likely, words and knowledge given by them were of secondary importance. It is sometimes difficult to recall what exactly they were talking about and it is not even important how they were doing that. But the presence of these people in our life, communication with them, their enthusiasm, their personal interest, responsibility and love for the work have considerably contributed to the formation of our views and moral beliefs.

This way, from the 'technical' point of view, dialogue develops critical abilities, develops the skill to pose questions, examine alternatives, understand paradoxes and note contradictions. Dialogue develops the ability to give definitions, pass from the semantic analysis of ethical terms to their pragmatic analysis, develops the power of reasoning and the ability to arrange points of view in order, the skill to build dialogue and carry on a conversation. Dialogue enhances the formation of moral beliefs and develops common humanitarian culture.

In addition, dialogue solves even broader humanistic problems. Dialogue helps a person to go outside the borders of his/her 'own self' into the world of the generally significant values. Shaping of values is a rather long and contradictory process. It requires a person to be interested, implies internal work, diligence and concern, but it does not imply immediate results. In the process of dialogue it is necessary to learn to listen to another person and to adequately react to what has been said. In the course of discussion and 
communication mental and discursive living through possible moral experience, allocation of roles, and detection of multivariance of escaping a moral collision is taking place. Daily activities and routine cause moral stale which atrophies the motivational sphere and threatens to convert a future specialist into the unprincipled, indifferent executor and bureaucrat. The dialogic approach becomes a means of training both moral and social responsibility of future specialists.

\section{Conclusion}

This way, the dialogic approach may be examined as a strategic direction in the development of ethical education. The essence of dialogic communication based on the Socratic method consists of the skill to accept the world of values of another person, to develop own spiritual and moral values, to conduct a spiritual dialogue, to formulate and defend one's point of view, to resolve contradictions, and to develop a system of values. It is fundamentally important to note that if attitude with preferred orientation to the knowledge reflects the ability of a student to acquire and reproduce data and ethical information, then attitude with orientation to the dialogue supports education aimed at the cultivation of ethical competence. Dialogue becomes a procedure leading to the development of a student's viewpoint which is more important than acquiring the rules of conduct, standards of morals and non-critical abidance by the requirements of moral codes. Pedagogical activity with the attitude towards the creation of dialogue introduces a student to the values the acquisition of which will contribute to the development of future specialist's ethical competence.

\section{References}

Aronowitz, S., Giroux, H. (1991). Postmodern Education: Politics, Culture and Social Criticism. Minneapolis MN: University of Minnesota Press

Gadamer, H. G. (1975). Truth and method. N.Y.: The Seabury Press.

Айзексон, У. (2013). Бенджамин Франклин. Биография. Москва: «Манн, Иванов и Фербер».

Бахтин, М. (1986). Эстетика словесного творчества. Москва: Художественная литература.

Бубер, М. (1995). Я и Tbl. // Два образа верыл. Москва: Наука.

Зинченко, В. (1996). Мир образования и/или образование мира. Москва: Мир образования.

Лиотар, Ж.-Ф.(1998). Состояние постмодерна. Москва, Институт экспериментальной социологии: Алетейя. 